\title{
Cryptocurrency as a factor for National Payment System Improvement in the process of Economy's digitalization
}

\author{
Oksana Sorokina ${ }^{1}$, Egor Dudukalov ${ }^{2}$, Liudmila Guzikova ${ }^{3}$, and Denis Ushakov , * $^{4}$ \\ ${ }^{1}$ Rostov State Transport University, Rostov-on-Don, Russia \\ ${ }^{2}$ Russian Presidential Academy of National Economy and Public Administration, South Institute of \\ Management, Rostov-on-Don, Russia \\ ${ }^{3}$ Saint-Petersburg Polytechnic University, Saint Petersburg, Russia \\ ${ }^{4}$ SuanSunandhaRajabhat University, Bangkok, Thailand
}

\begin{abstract}
Research develops the modern theory and methodology of cryptocurrency functioning as an integral part of modern money circulation, and the main directions of cryptocurrency progress as means of legal payment in the Republic of Indonesia. Based on the econometric model of the cryptocurrency main indicators influence the relationship between "bitcoin" attributes was assessed; the probable scenarios for the financial regulation system of the Republic of Indonesia (RI) effectivization based on the National Bank or special financial institutions competences were highlighted; the practical recommendations aimed at combating money laundering in cryptocurrency-based transactions have been developed from the position of priority for Indonesian payment system modernization.
\end{abstract}

\section{Introduction}

Today, due to the active development of the Internet, along with the technological processing innovations and modern encryption tools improvement cryptocurrency is the most popular and, at the same time, the least studied tool in the field of monetary circulation. Cryptocurrency represents, on the one hand, a peculiar and contradictory phenomenon in the modern financial services market, and on the other, a global system, which is developing more and more rapidly. There are more than 1,300 varieties of cryptocurrencies today!

In fact, cryptocurrencies replace real money in relationships between economic entities, in payment transactions on purchasing or obligations repayment to the state (for example) [1]. In practice, the emission of money substitutes is a source of such negative economic processes as an non-payment of wages increase, significant deformation of the level of the cost of goods (works, services) and, hence, deviation of prices, the formation of closed (shadow) financial systems, the flourishing of corruption along with the subsequent increase of barter scheme based transactions.

\footnotetext{
*Corresponding author: denis.us@ssru.ac.th
} 
One way or another all these reasons will trouble the system of economic relations.

Nevertheless, despite the categorical attitude of the state regarding any issue of cryptocurrency legalizing and its multiple attempts to prohibit the functioning of cryptocurrency as a payment instrument, there is no comprehensive information regarding the boundaries of the permitted activities of the considered instrument of monetary settlement.

Considering the above, the problem of the cryptocurrency functioning on an equal basis with the eligible means of payment today should be recognized as very relevant.

The purpose of the study is to develop scientific foundations and practical recommendations for the cryptocurrency functioning in the system of modern economic relations of the Republic of Indonesia (RI).

In accordance with this purpose, the main objectives of the study are formulated:

1) substantiate the specifics of the cryptocurrency modern use from the standpoint of correlation and regression analysis;

2) characterize and systematize the main trends in the cryptocurrency development, offer recommendations for the national payment system improving in the context of the cryptocurrencies legalization in Indonesia;

3) develop recommendations and financial measures to combat money laundering in the field of cryptocurrency circulation.

Theoretical and statistical foundations of the research

One of the most popular forms of cryptocurrencies in 2021 was bitcoin $[2,3]$.

Tab. 1 presents a list of the most promising cryptocurrencies, as of 2021, depending on indicators such as the level of market capitalization, popularity, price per unit of cryptocurrency [4].

Table 1. Top-10 of cryptocurrencies, as of 2021 [4].

\begin{tabular}{|c|l|c|}
\hline$\#$ & \multicolumn{1}{|c|}{ Cryptocurrencies } & $\begin{array}{c}\text { Market Capitalization } \\
\text { Bln., USD }\end{array}$ \\
\hline 1 & Bitcoin (BTC) & 128 \\
\hline 2 & Ethereum (ETH) & 19.4 \\
\hline 3 & XRP (XRP) & 8.22 \\
\hline 4 & Tether (USDT) & 6.4 \\
\hline 5 & Bitcoin Cash (BCH) & 4.1 \\
\hline 6 & Bitcoin SV (BSV) & 3.4 \\
\hline 7 & Litecoin (LTC) & 2.6 \\
\hline 8 & EOS (EOS) & 2.4 \\
\hline 9 & Binance Coin (BNB) & 2.4 \\
\hline 10 & Tezos (XTZ) & 1.5 \\
\hline
\end{tabular}

According to the data presented in Tab. 1, the rating of the most popular cryptocurrency in 2021 was headed by bitcoin. From the standpoint of the indicator of the price per unit of currency, "bitcoin" is the most expensive among all existing digital counterparts.

Based on this, the bitcoin is leading in comparison with its competitors (first of all, Ethereum, Ripple and Litecoin) in almost all indicators: at the level of market capitalization, at the price per unit of currency and on the prospects for further use.

Bitcoin is a new generation of payment tools. It functions as a new type of digital currency that can be used to conduct transactions online. By itself, the unit of calculation bitcoin is nothing more than a unique cryptographic code that cannot be used more than once.Cryptocurrency "bitcoin", like the generally recognized currencies "euro" and "dollar", has its own exchange rate for a specific date [5].

Working with bitcoin is carried out using one of two special programs [6]: 
1) "a virtual wallet:, which is a kind of bitcoin storage, with such a tool help user can conduct transactions for the cryptocurrency purchase or sale;

2) programsthat help bitcoins' "mining" - this tool copes with the difficult tasks of approving transactions for new bitcoins obtaining. In addition to programs for bitcoins' obtaining the services of online exchanges can be used [7].

The actual procedure for bitcoin miningis a very complex process, the basis of which is a solution of special mathematical problems [8]. The essence of the bitcoin mining procedure is to select a key (correct hash code) for a given algorithm. In the process of solving mathematical problems bitcoins are generated.

One of the most common modern phenomena is teamwork, namely the pooling of several miners. This allows to get more bitcoinswith lower costs. However, this method of bitcoin mining is currently less profitable due to the rise in the price of computer components. The most practical type of bitcoin mining today are bitcoin farms. They are large industrial companies that professionally mine bitcoins. One of these farms is located in Hong Kong and its computing power is over $4 \%$ of the entire Bitcoin network. The level of its daily production of bitcoin is about 26 units [9].

\section{Methodology of the study}

The degree of influence of the bitcoin price (per unit) on the bitcoin market capitalization can be tested by correlation-regression analysis. The use of this method of statistical analysis helps to establish the nature and quantitative expression of the relationship between the above indicators of the studied cryptocurrency.

The basic and calculated data for the statistical model formation using correlationregression analysis are the indicators of the price per unit of the bitcoin and the level of capitalization of the analyzed monetary surrogate for the period from 2014 to 2020.

Having examined the system of indicators it can be assumed that within the modern economy frameworks within the growth of the cryptocurrency price the market capitalization of the analyzed virtual currency also increases.

A graphical representation of the bitcoin price is shown in Fig. 1, and the indicator of the bitcoin market capitalization is shown in Fig. 2.

According to the data in Fig. 1, we can formulate the following conclusion: despite the prevailing trend of bitcoin price increase in the analyzed period, there is an abrupt change.

Thus, the considered indicator in the period from January 2017 to January 2021 increased by almost 14 times, which indicates the volatile nature of the bitcoin. According to the information shown in Fig. 2, we can talk about the similarity traced between the graph of the dynamics of the time series of the bitcoin price and the graph of the dynamics of the time series of bitcoin market capitalization.It is also important that the unevenness, which determines the ups and downs of indicators of the bitcoin price and bitcoin market capitalization, is explained, in the authors' opinion, by a sharp increase in interest on the part of economic entities in the bitcoin and, how a consequence of the annually increasing bitcoins'demand. 


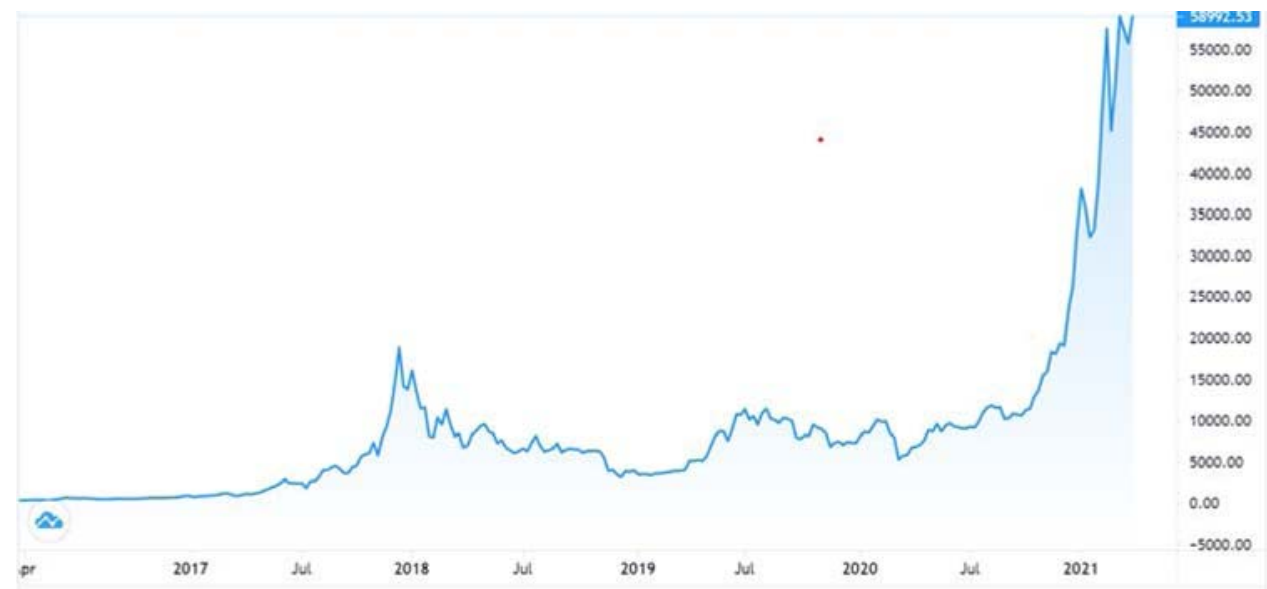

Fig. 1. Price of bitcoin [4].

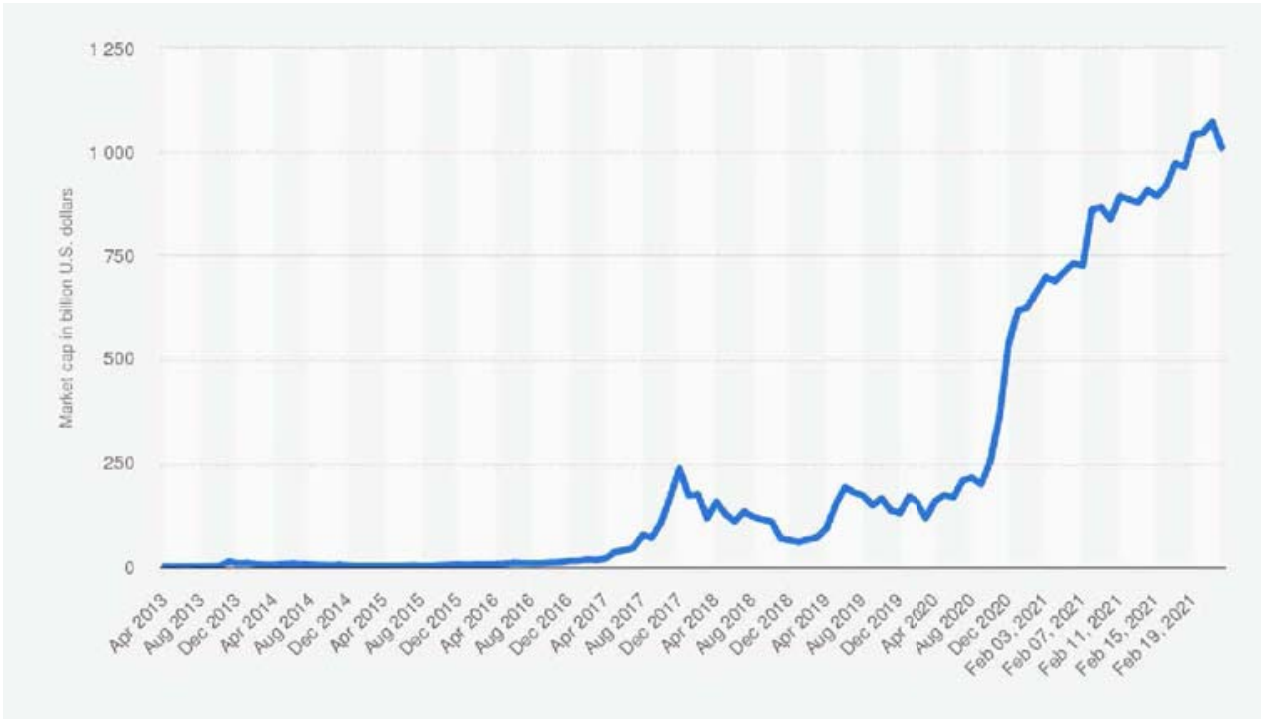

Fig. 2. Bitcoin market capitalization [11].

The interdependence of the analyzed features of the bitcoin can be described by the mathematical equation of a simple linear regression

$$
Y_{n}=a_{0}+a_{1} x_{1}+\ldots . a_{n} x_{n}
$$

Where: a -is regression coefficients;

$\mathrm{x}-$ is an influencing factor (price per unit of bitcoin, USD);

$\mathrm{n}$-is the number of analyzed years;

$\mathrm{Y}$-is the indicator of the market capitalization of the bitcoin, USD.

In order to identify the relationship between the price indicators for 1 bitcoin and the level of bitcoins' market capitalization we will supplement the original data with data for calculating the parameters of the regression equation.

Tab. 2 shows the calculation of the parameters of the regression equation. 
Table 2. Calculation of the parameters of the regression equation.

\begin{tabular}{|c|c|c|c|}
\hline & $\mathbf{X}_{\mathbf{1}}$ & $\mathbf{Y}_{\mathbf{1}}$ & $\mathbf{X}_{\mathbf{1}^{\mathbf{2}}}$ \\
\hline $\mathbf{1}$ & $\mathbf{2}$ & $\mathbf{3}$ & $\mathbf{4}$ \\
\hline 02.01 .2014 & 771.15 & 9400260663 & 594672 \\
\hline 02.01 .2015 & 313.64 & 4289287759 & 98370 \\
\hline 01.01 .2016 & 434.22 & 6527492315 & 88547 \\
\hline 01.01 .2017 & 972.95 & 156441622845 & 946631 \\
\hline 01.01 .2018 & 13791.6 & 231350986890 & 190208230 \\
\hline & 16283.56 & 408009650472 & 192036451 \\
\hline
\end{tabular}

\begin{tabular}{|c|c|c|}
\hline & $\mathbf{Y}_{\mathbf{1}}{ }^{\mathbf{2}}\left(\mathbf{X}^{\mathbf{1 8}}\right)$ & $\mathbf{X}_{\mathbf{1}}{ }^{\mathbf{2}}\left(\mathbf{X ~ 1 0} \mathbf{1 0}^{\mathbf{1 2}}\right)$ \\
\hline $\mathbf{1}$ & $\mathbf{5}$ & $\mathbf{6}$ \\
\hline 02.01 .2014 & 88.364 & 7.249 \\
\hline 02.01 .2015 & 18.397 & 1.345 \\
\hline 01.01 .2016 & 42.608 & 2.834 \\
\hline 01.01 .2017 & 24473.981 & 152.209 \\
\hline 01.01 .2018 & 53523.279 & 3190.7 \\
\hline & 78146.631 & 3354.338 \\
\hline
\end{tabular}

Now we can calculate the average values of the indicators:

$$
\bar{x}=\frac{1}{n} \sum_{i=1}^{n} x ; \overline{x^{2}}=\frac{1}{n} \sum_{i=1}^{n} x
$$

In order to determine the parameters of the mathematical equation of the straight line

$$
Y_{X}=a+b x
$$

the system of equations should be solved using the formula (3)

$$
\left\{\begin{array}{c}
n a+b \sum x=\sum y \\
a \sum x+b \sum x^{2}=\sum x y
\end{array}\right.
$$

Thus, the regression coefficient is $b=14,571,849.03$.

Since $\mathrm{b}>0$, there is a direct relationship between the parameters $\mathrm{x}$ and $\mathrm{y}$.

Let's check the obtained value of the correlation coefficient according to the Chaddock table. The obtained value of the indicator $r$ is in the range from 0.7 to 1.0 .

This indicates the presence of a strong direct correlation between the indicators of the bitcoin price and bitcoin market capitalization. In other words, directly with the growth of the price for 1 bitcoin, the size of the market capitalization of the bitcoin will increase and vice versa.

Summing up the analysis results, it should be noted the high popularity of cryptocurrency.

As an objective of this research, the determination of parameters of the regression equation using the example of the value of bitcoin market capitalization and the further establishment of the degree of closeness of the analyzed relationship should be considered.

At the first stage, a mathematical equation of simple linear regression was modeled and the value of the correlation coefficient was determined based on data from the Chaddock table to establish the level of relationship between the model's parameters.

The obtained value of the indicator shows the presence of a strong correlation between the analyzed parameters of the equation.

The results of the study determined the unreliability of the regression equation under consideration. The results obtained throughout all stages of the statistical analysis prove the duality of the nature of the investigated instrument of "monetary surrogate", since when considering the regression models, only one of the three declared criteria determined the 
effectiveness of the model under consideration (the first stage is the determination of the correlation coefficient in comparison with the Chaddock table criteria).

\section{Results and findings}

In modern realities, the most important attribute of a successfully developing economy is its susceptibility to innovations and a competent organization of the system of their control. Active digital interaction between economic entities serves as a guarantee of the economic development of the state, the prospect of which is forming also through the study and practical application of recently emerged financial instruments [13].

One of the primary issues in the context of the problem of bitcoin functioning today is its regulation (tab. 4).

Table 4. Regulation of bitcoin in different countries (2019, made by co-authors) [14].

\begin{tabular}{|l|l|}
\hline \multicolumn{1}{|c|}{ Features of the regulation } & \multicolumn{1}{|c|}{ Countries } \\
\hline $\begin{array}{l}\text { Development of a regulatory } \\
\text { framework } \\
\text { due to the active introduction of digital } \\
\text { currency to the country's economy }\end{array}$ & $\begin{array}{l}\text { Australia, Brazil, Canada, Colombia,Croatia, } \\
\text { Czech Republic, Cyprus, Denmark,France, } \\
\text { Ukraine, Hong Kong, Israel,Italy, Japan, } \\
\text { Singapore,Slovenia, Soland, Norway, Poland, } \\
\text { Spain,Switzerland, Sweden, Turkey,UK, USA, } \\
\text { Virgin Islands,Republic of Belarus }\end{array}$ \\
\hline $\begin{array}{l}\text { Identification of cryptocurrencieswith } \\
\text { property }\end{array}$ & USA \\
\hline $\begin{array}{l}\text { Identification of cryptocurrency as } \\
\text { illegal; prohibition (restriction) } \\
\text { for its functioning }\end{array}$ & $\begin{array}{l}\text { Bangladesh, Bolivia, China, Ecuador,Iceland, } \\
\text { Indonesia, Kyrgyzstan, Lebanon,Russia, } \\
\text { Thailand, Vietnam }\end{array}$ \\
\hline $\begin{array}{l}\text { Introduction of VAT on transactions } \\
\text { based ondigital currencies }\end{array}$ & USA, Australia, Israel \\
\hline $\begin{array}{l}\text { Establishing ATMs for work } \\
\text { with cryptocurrency }\end{array}$ & $\begin{array}{l}\text { Germany, Canada, Switzerland, Slovakia,Czech } \\
\text { Republic, Ukraine, Hungary }\end{array}$ \\
\hline $\begin{array}{l}\text { Bitcoin as a special kind of financial } \\
\text { transaction }\end{array}$ & \begin{tabular}{l} 
Finland, Belgium \\
\hline
\end{tabular} \\
\hline
\end{tabular}

After analyzing the data from Tab. 4, the features characterizing foreign experience of cryptocurrencies legal regulation can be identified:

1) despite the high level of foreign governments interest there is a sharp lack of prospects for solving the existing difficulties associated to specification of bitcoins' place in monetary and financial system;

2) cryptocurrency's recognition as an alternative to traditional currencies of the analyzed countries, it cannot be interpreted as a financial product;

3 ) the lack of a comprehensively developed system to effectively regulate activities with cryptocurrencies.

Less than half of all considered cryptocurrency companies are geographically located in the United States. The second most attractive country for doing business based on cryptocurrency is the UK - about $12.3 \%$ of all analyzed companies. They are followed by the British Virgin Islands, China, Canada, Ireland and Singapore. The least attractive countries were Norway and Finland - 1.6\% of companies from the total list each [15].

Analyzed the current practical approaches to the cryptocurrency regulation implementing in foreign countries, a tendency, characterized by a lack of consensus regarding the analyzed economic instrument was clearly revealed.

From the point of foreign countries experience: some countries are developing a regulatory framework in order to actively introduce digital currency into their economies, 
others - classify the bitcoin currency as a special (non-trivial) financial transaction, and others, the most conservative ones, still introduce a complete ban on the bitcoin functioning, and some countries even consider bitcoin as property [16, 17, 18].

Summarizing all of the above, we can conclude that today there is no comprehensive methodology that would equally ensure the security of payments based on virtual currencies transactions, along with the introduction of a complete ban on their use in the field of shadow business and related industries, and to maintain their positive characteristics of virtual currency.

But despite all the shortcomings inherent in cryptocurrencies in the form of digital currency, representatives of most of the analyzed countries agreed that cryptocurrency is the financial instrument of the future.

In the course of studying the problem of cryptocurrency functioning in the system of modern economic relations, a tendency that characterizes the absence of a unified system providing an adequate level of protection was revealed.

The conducted study focused on such functions of cryptocurrencies management as modeling the conditions for their formation and, as a result, forecasting the most likely course of events.

Forecasting within the framework of the study should be considered from the point of identifying acceptable options for the further cryptocurrency functioning.

Three forecasts of cryptocurrency regulation in Indonesia can be offered.

A pessimistic scenario, suggesting the prospect of a complete ban on cryptocurrencies, will keep Indonesia on a par with countries such as Bangladesh, Bolivia, Kyrgyzstan, and Ecuador. Of course, if prohibiting the use of virtual currencies continuous the following trends will be observed:

1) minimization of operations directly related to cryptocurrency, however, this will negatively affect business and foreign investments, the outflow of IT specialists is possible;

2) reducing the threat to the national currency stability from cryptocurrencies;

3) minimization of the risks of capital outflow, money laundering and terrorist financing;

4) an increase of the shadow turnover of funds;

5) withdrawal of cryptocurrency transactions to other jurisdictions (for example, Singapore).

In addition, at this time, Indonesia does not have the necessary technical equipment, financial component and competencies to implement a full-fledged assessment and control over operations based on virtual currency. It should also be noted that if the government of the country continuous prohibiting cryptocurrencies transactions Indonesia can become a center for the formation and further development of technologies based on anonymous transactions. As a result, it will be impossible for legal business schemes based on digital currencies to function, which, in turn, will affect external investments.

In addition, if such ban keeps lots of foreign citizens and companies in Indonesia can be included in the category of violators.

Another option, based on an optimistic scenario of the development, is based on the idea of cryptocurrencies regulating in the territory of the RI. To implement this option, prerequisites are the formation of a legal framework for working with cryptocurrency; the official recognition of cryptocurrency as a legitimate means of payment. It will contribute to the development of positive experience in using virtual currency, which will result in:

1) obtaining statistical data on the cryptocurrencies use and monitoring;

2) control over operations and identification;

3) possibility of effective restrictions on volumes and operations;

4) possibility of arbitration within the framework of regulation and establishment of liability. 
On the other hand, the legalization of cryptocurrency can entail negative consequences, expressed in the following points:

1) likelihood of increasing the interest of citizens to invest in cryptocurrencies and potentially increasing the risks of losing funds;

2) possibility of using unscrupulous and fraudulent schemes and the appearance of a shadow turnover of funds. The last option - probable - is the most relevant today due to the uncertainty of the country's government regarding the problem of virtual currencies regulating. It postpones the solution of the problem of cryptocurrencies functioning for an indefinite period, which will entail a decrease in the country globalstatus. Such an alternative will contribute to the impossibility of organizing monitoring of the funds movement and control over operations and identification in order to counter money laundering, an increase in the number of unfair and fraudulent schemes, the impossibility of arbitration of financial disputes in the legal field and an uncontrolled increase in the turnover of virtual currencies.

Thus, the most correct answer to the question "what to do with cryptocurrencies?" is their regulation.

However, before taking on the development of comprehensive legislation and its further implementation in order to ensure successful application practice, it is necessary to analyze the reasons that hinder the cryptocurrencies introduction into the Indonesian economy as legal means of payment. These factors include:

1) lack of an adequate level of security - this indicator is due to a shortage of information identification, and therefore, determining the contact information of the account user becomes an overwhelming task. This, in turn, contributes to the development of illegal forms of business;

2) reducing the role of the state as a single controller;

3 ) if the digital currency is officially recognized as a means of payment, the introduction of a new unit of account into circulation will deal a significant blow to the social sphere, this will lead to unemployment with all the ensuing consequences (the most striking example is the reduction in the number of bank personnel).

In modern conditions of the scientific and technological process development, in order to strengthen the cryptocurrency position in the RI system of monetary circulation it is necessary to develop provisions for a strategy for monitoring the cryptocurrencies activities, which is based on a set of measures consisting of several levels:

1. Legal (introduce an exhaustive interpretation of the financial instrument, define the term "cryptocurrency", and assign this form of money the status of a legitimate instrument of non-cash payments).

2. Organizational (introduce a procedure for licensing the activities of organizations related to cryptocurrency; establish requirements for exchanging traditional money for cryptocurrencies and in the reverse order in a ratio of 1:1.5; as well as impose a ban on the issue of cryptocurrency at a discount (in order to limit the likelihood of crypto-oriented organizations formation); create a reserve of traditional money against the security of cryptocurrency, in the amount of at least 70\%; appoint special companies (operators) as senders of cryptocurrency that have passed all levels of verification to obtain a license to carry out activities, related to cryptocurrencies, organize the process of cryptocurrencies issuing).

\section{Conclusions and recommendations}

Based on the assessment of the level of development dynamics of the currently popular forms of money substitutes within the global financial system, we firstly, studied in detail the experience of foreign countries for the functioning of the bitcoin as an eligible means of 
payment; revealed the lack of a comprehensive methodology in the context of the issue of establishing control over the modern forms of cryptocurrencies functioning.

Secondly, based on the results of scanning the modern forms of cryptocurrencies environment on the basis of systematization and generalization of strengths, weaknesses along with the probable threats and opportunities, we formulated the main advantages of cryptocurrencies legalizing.

On the basis of the correlation-regression method use an assessment of the cryptocurrencies phenomenon is given from the standpoint of statistical analysis.

On the basis of the data obtained, the impossibility of using some statistical indicators to the phenomenon of cryptocurrencies is argued, which is also evidence of the attribute of a dual nature inherent in the analyzed financial instrument.

The presented conclusions confirm the need for the development of the digital sphere by introducing modern forms of cryptocurrencies into the national economy.

By analyzing the options for organizing a system for activities of monetary surrogates regulating, we have modeled the likely prospects for the further use of modern forms of money substitutes in Indonesia if they are officially approved by government authorities in the context of the three most probable scenarios - pessimistic, optimistic and probable.

The last scenario turned out to be the most realistic option due to the lack of active actions on the part of the state on the development of a set of measures providing for control over the functioning of cryptocurrencies, and amending the current legislation regarding the legitimacy of existing forms of mutual settlements. Along with this, an assessment was made of the factors that hinder the construction of digital currencies in the domestic economy in the status of legal tender.

As the main recommendations for the application of the results obtained in the framework of the study, it is proposed to introduce a system of measures aimed at regulating the activities of modern forms of cryptocurrencies. Prospects for further development of the research topic are in the following areas:

- in the continuation of the study of the cryptocurrency instrument within the framework of a theoretical study from the standpoint of a statistical approach in order to identify the dependence of the market capitalization indicator of a certain type of cryptocurrencies on the currently known statistical coefficients;

- in monitoring the existing forms of monetary surrogates and forecasting the emergence of the most popular forms of money substitutes and in identifying their modifications;

- in a more detailed analysis of the current state of the monetary sphere from the position of clarifying the role of monetary surrogates in the economic life of an individual. The information obtained can be useful in the formation of regulatory documents aimed at regulating the circulation of cryptocurrencies.

\section{References}

1. A. Dyhrberg, Finance Res Lett 16, 85-92 (2016)

2. S. Nakamoto, Bitcoin: a peer-to-peer electronic cash system (Technical report, Manubot, 2019)

3. C. Dwork, M. Maor, Advances in cryptology - CRYPTO' 92 (Springer, Berlin, 1993)

4. Top 10 cryptocurrencies by market capitalization (2021) https://coinrivet.com/top-10cryptocurrencies-by-market-capitalisation/

5. C. Wu, V. Pandey, JFinanc Plan 27(9), 44-52 (2019)

6. J. B.Kim, H. Park, Int J Innov Technol Explor Eng 8(4S2), 459-463 (2019)

7. Y. Zhu et al., FinancInnov 3(1) (2017) 
8. L. Wang, Y. Liu, International conference on passive and active network measurement (Springer, 2019)

9. X. Jieyu et al., Peer-to-Peer Networking and Applications 14, 644-654 (2021)

10. E. Cheah, J. Fry, Econ Lett 130, 32-36 (2018)

11. Bitcoin market cap percentage bitcoin fees info (2021) http://заветка.pф/techniquealternative/bitcoin-market-cap-percentage-bitcoin-fees-info/

12. K. Christidis, M. Devetsikiotis, IEEE Access 4, 2292-2303 (2019)

13. S. Barber et al., International conference on financial cryptography and data security (Springer, 2018)

14. S. Dos Santos et al., IEEE international conference on blockchain (2019)

15. E. Dudukalov et al., E3S Web of Conferences 244, 10021 (2021)

16. M. Carlsten et al., Proceedings of the ACM SIGSAC conference on computer and communications security ACM, 154-167 (2019)

17. M. Crosby et al., Appl Innov 2(6-10), 71 (2017)

18. D. Kondor et al., PloS One 9(2), 86197 (2014) 